\title{
Um game inteligente que utiliza a interação como instrumento de metrificação e eficácia de ações colaborativas
}

\author{
Edgar Delbem ${ }^{1}$, Cláudia Lage Rebello da Motta ${ }^{1,2}$, Carla Verônica M. Marques ${ }^{1}$, \\ Carlo Emmanoel Tolla de Oliveira ${ }^{1,2}$
}

${ }^{1}$ Programa de Pós-graduação em Informática (PPGI) - Universidade Federal do Rio de Janeiro (UFRJ) - Rio de Janeiro - Brasil

${ }^{2}$ Núcleo de Computação Eletrônica (NCE) - Universidade Federal do Rio de Janeiro
Rio de Janeiro - RJ - Brasil
edelbemevesper.org.br, claudiamence.ufrj.br, carlos@nce.ufrj.br,
carlaveronica@nce.ufrj.br

\begin{abstract}
The article proposed using a game whose aim is to obtain data unaware of the cognitive executive functions that are linked as interactions between participants in the working group. The proposed multiplayer game is a tool to measure the level of anachronistic self-centeredness in high school. The action research methodology was used to recognize students' interrelational and interactive processes. The theoretical framework was "Educational Psychogenetics". The game "Meggido", a measuring instrument of this research, was able to capture the levels of disarticulations between the two forming of the human brain-mind binomial: the somesthetic and the psychic. The predominant measure that reveals the main communication channels and strong areas of family knowledge [INHELDER, 1996], which can be used as a path to protagonist learning.
\end{abstract}

Resumo. O artigo propõe uso de game cujo finalidade é a obtenção de dados inconsciente das funções executivas cognitivas que estão atreladas as interações entre participantes do grupo de trabalho. O game multiplayer proposto é ferramenta para mensurar o nível de egocentrismo anacrônico no ensino médio. Foi utilizado a metodologia de pesquisa-ação para reconhecer os processos inter-relacionais e interativos dos estudantes. O referencial teórico foi a "Psicogenética Educacional". O game "Meggido", instrumento de mensuração desta pesquisa, foi capaz de capturar os níveis de desarticulações entre as duas instâncias formadoras do binômio cérebro-mente humano: a somestésica e a psíquica. A instância predominante medida revela os canais principais de comunicação e áreas fortes de conhecimento familiares [INHELDER, 1996], que possam ser utilizadas como caminho para a aprendizagem protagonista.

\section{Introdução}

Os games estão cada vez mais populares na sociedade contemporânea, especialmente entre os jovens. Como a área de pesquisa de combinação de conceitos de aprendizagem baseada em jogos computacionais sérios são mais recentes [Wendel 2013], faz-se necessário um aprofundamento nas práticas de aplicações pedagógicas associadas aos métodos de gamificação. Em particular, o estudo relacionado aos games multiplayers colaborativos como instrumento de mensuração do perfil cognitivo dos jogadores. 
Em sua revisão sistemática, Marc Palaus et al. (2017) afirmam que muitos destes estudos se concentraram no sistema neural e efeitos comportamentais dos videogames. E que "apesar da heterogeneidade inata do campo de estudo, tem sido possível estabelecer uma série de ligações entre os aspectos neurais e cognitivos, particularmente em relação à atenção, controle cognitivo, habilidades visuais e espaciais, carga de trabalho cognitiva e recompensa em processamento".

Este artigo apresenta um game multiplayer construído com base no design cuja finalidade é intencionalmente concebida para remeter à externalização inconsciente das funções executivas cognitivas atreladas ao engajamento motivacional, para a promoção das trocas assertivas entre participantes de um grupo de trabalho. Este game é utilizado como instrumento de mensuração capaz de medir a qualidade da colaboração durante o jogo, entre os alunos do ensino médio.

\section{Contexto}

A implementação de tecnologias como ferramentas de apoio a aprendizagem é uma realidade necessária para a melhoria do desenvolvimento de práticas de Ensino mais eficazes, principalmente considerando os tempos de educação digital e híbridos que estamos vivendo por conta da pandemia.

Como podemos ver em [Moura 2020] nos últimos anos as escolas têm enfrentado dificuldades na implementação de tecnologias como ferramentas de apoio e estímulo a aprendizagem, e estas

A natureza humana tem como dinâmica a capacidade de comunicação que propulsiona o processo de desenvolvimento da espécie. A colaboração é um dos seus atributos que conta com esta qualidade comunicativa para fazer os intercâmbios necessários. No processo

colaborativo é possível detectar as dificuldades de desenvolvimento e de relacionamento, além de criar soluções novas a partir do diálogo dos participantes do grupo.

Neste contexto, esta pesquisa considera os alunos do ensino médio em dois horizontes: o das suas qualidades das interações com o universo objetal e o das suas qualidades de inter- relações 1 com outras pessoas. O nosso problema é: como identificar o perfil de cada estudante a fim de incentivá-lo a usar suas competências pioneiras para ampliar sua capacidade de colaboração?

\section{Fundamentação Teórica}

Joaquim Ferreira Xavier Jr. expandiu a Teoria da Psicogenética de Jean Piaget [PIAGET 1964]. Ele inicia seu livro: "A PSICOGENÉTICA - Demarcando os Processos da vida"[XAVIER JR, 2004] enfatizando sua proposta.

A observação Psicogenética desenvolveu seu foco Interacional instigada pelo pensamento epistemológico de Piaget [PIAGET 1964], psicólogo do desenvolvimento que sinalizou e supôs, mas não mapeou nem organizou, os elementos do Envolvimento Interacional. Em seus estudos, Xavier discorreu sobre a teoria "Interaciológica" do desenvolvimento. "No genoma existem os sinais interacionais da espécie humana, mas a Energia Interacional da Pessoa somente é 
consumada pela ativação do ambiente adulto".

\section{Trabalhos Relacionados}

Wendel et a. (2013) apresenta uma abordagem para o design de cenários de aprendizagem colaborativa baseados em jogos usando Serious Games multijogador. Krause, Hounsell \& Gasparini (2020) apresentam um modelo para inter-relação entre funções executivas e elementos de jogos digitais. Ambos os trabalhos apresentam propostas para desenvolvimento acadêmico dos estudantes no entanto os mesmos modelos não configuram necessariamente uma gamificação colaborativa, ou seja, com interação on-live dos alunos, o que não permite a construção do saber coletivo dinâmico com todos jogando e aprendendo coletivamente em uma mesma Plataforma.

Bavelier et al. (2012) apresentam bases neurais de atenção seletiva em jogadores de videogame de ação. Vosselet al. (2014) pesquisa sobre sistemas de atenção dorsal e ventral: circuitos neurais distintos com papéis colaborativos. Através da pesquisa de Bavelier é possível compreender como funcionam e se estabelecem as bases neurais dos jogadores durante a partida, o que nos permite identificar padrões de comportamentos nos alunos enquanto estes jogam coletivamente.

Oliveira et al. (2019) propõe e usa uma metodologia adaptada, um protocolo de avaliação do jogo e aprendizagem e instrumentos de coleta de dados (perfil, reação, aprendizagem e comparação de jogos). Através da pesquisa de Oliveira foi possível criar um protocolo de avaliação da aprendizagem dos alunos através da interação dos mesmos tendo como base a sua pesquisa desenvolvida que conta com uma metodologia de coleta de dados que considera o perfil, a reação e a aprendizagem dos estudantes.

Segundo Moura (2020) através da utilização de frameworks e ferramentas de Tecnologias da Informação e Comunicação é possível estimular os alunos academicamente e melhorar o rendimento escolar dos estudantes através da aprendizagem colaborativa.

\section{Objetivo}

O objetivo deste trabalho é mensurar a qualidade das manifestações de interação de cada indivíduo dentro do contexto de trabalho de grupo colaborativo, identificando o grau de "expressivação" (manifestação autêntica) da identidade competente, isto é, as pioneiras assim como as suas dosagens para demarcar e manter espaços de atuação de áreas de força, em contraposição à exigências inadequadas de outros participantes do grupo [Xavier Jr, 2004].

No caso de o indivíduo estar consciente de suas competências pioneiras, torna-se ele capaz de realizar a metacognição daquilo que sabe e daquilo que não sabe "FOK" (Feeling of Knowing) e "FONK" (Feeling of Not Knowing) [SHIMAMURA, A. P. 1994], sobre as competências próprias e as dos outros, viabilizando o trabalho colaborativo do tipo seletivo (agrupamento por qualidades complementares).

O objetivo geral desta pesquisa é demonstrar o avanço na qualidade inter- 
relacional e cognitiva dos alunos do ensino médio, valendo-se do jogo computacional colaborativo (Meggido) para mensurar o nível da articulação das instâncias 'somestesia' e 'psiquismo' e o anacronismo. Considera-se que a cognição de qualidade implica em inter-relacionalidade e não somente em relacionamentos sociais, visto que a intencionalidade evolui quando constrói vínculos de qualidade, interativos com o ambiente físico e inter-relacionais com o ambiente humano.

\section{Metodologia}

Foi utilizada a metodologia de pesquisa-ação para reconhecer os processos interrelacionais e interativos dos estudantes dentro do ambiente escolar. Após a coleta e a análise de dados, que primeiramenta aconteceu através de uma entrevista com os alunos que teve como finalidade mapear os agrupamentos presentes dentro daquele grupo em específico (Agrupamento Tribal: definimos como tipo de agrupamento onde os alunos se junto apenas por afinidade; e Agrupamento Seletivo: definimos como tipo de agrupamento onde os alunos se juntam tendo em vista o desenvolvimento de uma tarefa e um objetivo a ser alcançado, como por exemplo um trabalho em grupo ou uma prova em dupla).

Segundo os princípios do referencial teórico utilizado: a "Psicogenética Educacional", o game "Meggido" foi elaborado e utilizado como instrumento de mensuração desta pesquisa.

O game foi capaz de capturar os níveis de desarticulações entre as duas instâncias formadoras do binômio cérebro-mente humano: as instâncias somestésica (que de forma surperficial, pode ser entendido como habilidades que exigem coordenação motora, como esportes e atividades físicas por exemplo) e a psíquica (que simplificadamente pode sem entendido como habilidades intelectivas como facilidade com abstrações, maior concentração em atividades onde a cognição e pensamento são exigidos) bem como a instância predominante de cada estudante (que são as características marcantes de cada indivíduo, considerando que todos possuem capacidades somestésicas e psiquícas mas uma delas tem maior predominância sobre o indivíduo que a outra), revelando ao professor os canais principais de comunicação (áudio-fonético ou viso-motor) e áreas fortes de conhecimento familiares [INHELDER, 1996], que possam ser utilizadas como "ponte" para a aprendizagem protagonista.

\subsection{População amostral}

Esta pesquisa foi realizada com uma amostra contendo 450 estudantes entre a primeira e terceira série do Ensino Médio de uma Rede de Ensino particular que possui filiais no Rio de Janeiro e em São Paulo, onde foram realizadas as aplicações do Meggido, contando ainda com a participação de cinquenta professores, aproximadamente. O Meggido foi aplicado através de classmates (One Laptop per Child - OLPC) e em laboratórios de informática. Os experimentos foram realizados em dois momentos, aqui denominados por cenários. Os dois cenários que foram trabalhados pelos alunos do Ensino Médio no período de três meses podem ser observados nas figuras 1 e 2 . 
No primeiro cenário, foram utilizados dois crivos: sendo o primeiro um crivo empírico, que resultou do confronto das atividades empíricas dos alunos com os indicadores/padrões, aplicados pelos professores para avaliar o grupo controle e o segundo um crivo computacional das ações dos participantes através de softwares satélites do Diachronic (que é o conjunto de games desenvolvidos, o qual contemplamos apenas o Meggido neste artigo). Neste segundo cenário, os alunos trabalharam com os classmates (que são uma espécie de notebook adaptados para utilização em sala de aula) em grupos com até seis participantes e cada um portando o seu. Num primeiro momento (Figura 1), eles se juntaram em grupos livres (enturmação tribal) e, no segundo momento (Figura 2), reuniram-se em grupos dirigidos segundo as suas especialidades (enturmação seletiva).
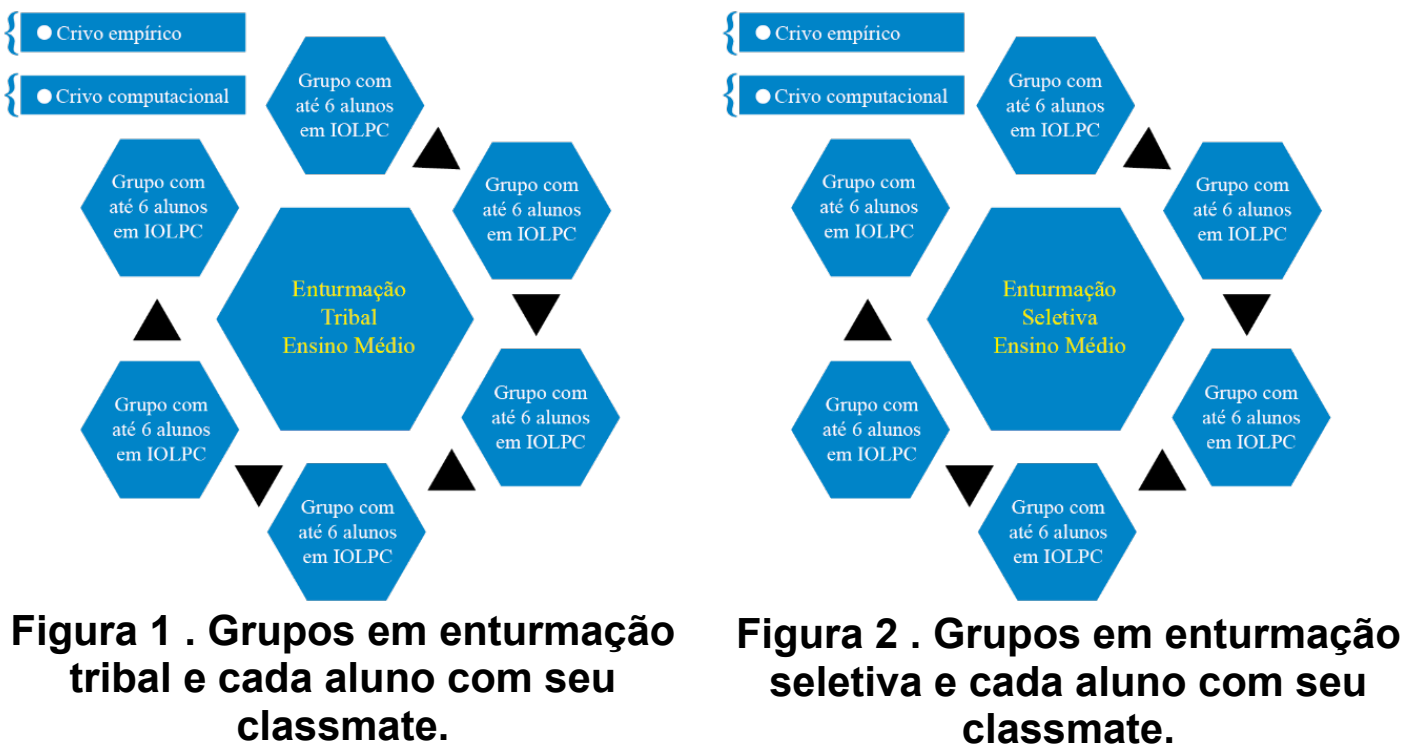

\subsection{Natureza do instrumento}

Para participar do jogo é preciso que todos os participantes trabalhem em regime colaborativo e que sejam produtivos. Através do Meggido é possível observar as competências pioneiras, sejam elas de humanas ou de exatas. Uma vez conhecidas, as competências naturalmente se organizam para atuação interaciológica complementar. Isto se reflete numa composição de equipes de trabalho com enturmação seletiva.

O Meggido foi desenvolvido com o propósito de ser um jogo multijogador cooperativo, calibrado para ser jogado por grupos de quatro a seis pessoas. Durante a realização do jogo, um jogador pode assumir diversas atividades. Cada atividade foi planejada visando refletir o regime do funcionamento humano da articulação das instâncias (somestesia e psiquismo) permitindo, através da mensuração dessas atividades, definir a tendência que um jogador apresenta. O mapeamento das atividades para cada regime do funcionamento das articulações das instâncias será apresentado no final desta seção, após as atividades terem sido descritas.

O jogo consiste de um cenário espacial com um planeta centrado na tela. No interior deste planeta existe um mapa formado por várias partes. O objetivo do jogo é pintar todos os pedaços do mapa, de tal forma que pedaços vizinhos não possuam a mesma cor. Para a realização da atividade de pintura, o jogo apresenta 
quatro canetas. Cada jogador pode selecionar uma caneta por vez, entretanto, quando uma caneta é selecionada ela fica indisponível para os outros jogadores. Na Figura 3, é apresentada a tela do jogo com o mapa e as canetas.

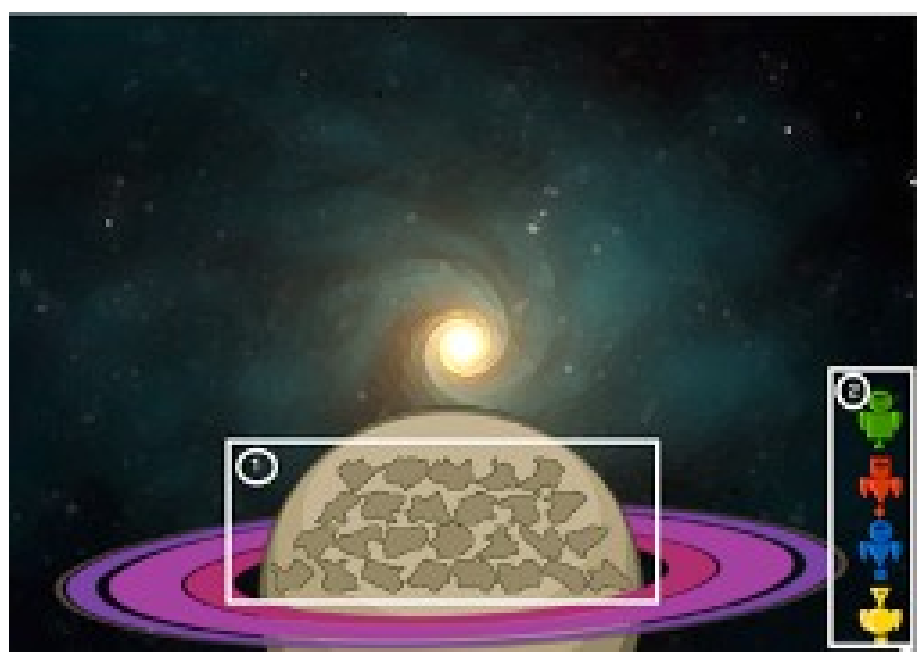

Figura 3 . Tela do Meggido - mapa e canetas para pintar

A atividade de pintura do mapa é dificultada por dois elementos do jogo: uma restrição na própria atividade de pintura e naves inimigas que disparam projéteis contra o planeta. A restrição para a atividade de pintar o mapa define que se uma parte do mapa for pintada com uma cor igual a cor de uma outra parte que faça fronteira com esta, todo o mapa será limpo, ou seja, todas as cores atribuídas a todos os pedaços do mapa são removidos. As naves inimigas realizam disparos em intervalos aleatórios, com média de 20 disparos por minuto. Toda vez que um desses projéteis atinge o planeta, o mapa é limpo. Na Figura 4 podemos ver como as naves inimigas são apresentadas em conjunto com um projétil que a nave da esquerda lançou.

Para que seja possível atingir o objetivo do jogo, os jogadores podem defender os projéteis com robôs defensores - como podemos ver na Figura 4 posicionando-os na frente desses projéteis. Para que a defesa seja efetiva, a cor e forma do robô defensor devem ser idêntica a cor e a forma do projétil lançado pela

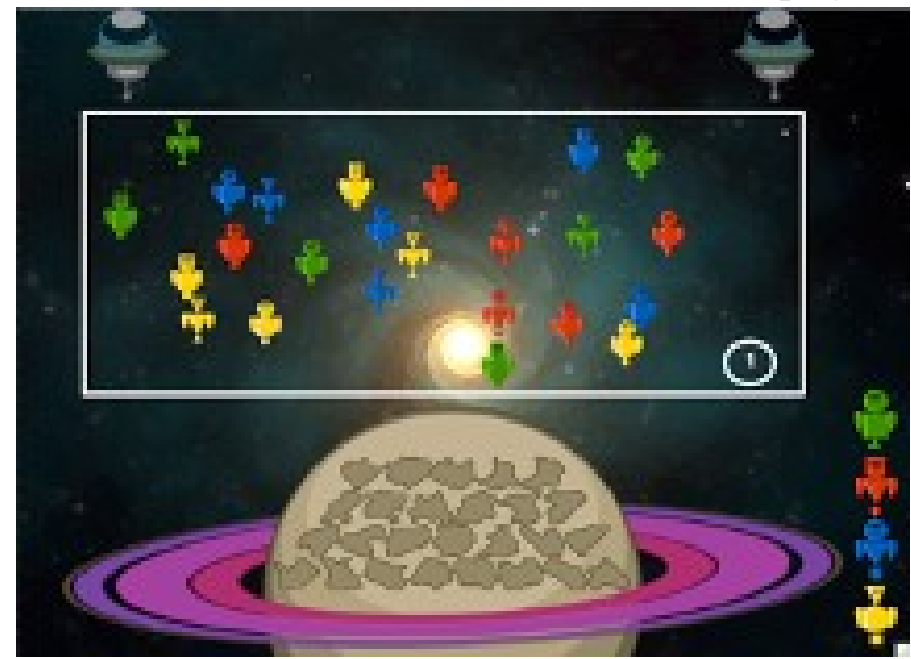

Figura 4 . Robôs defensores do jogo 
nave inimiga. No Meggido existem um total de quatro cores (verde, vermelho, azul e verde) e três formas (quadrado, círculo e triângulo). O número total de robôs defensores presentes no jogo é 24 sendo dois robôs de cada cor e forma.

Quando um projétil atinge um dos robôs defensores da mesma forma e cor, o projétil e o robô são destruídos, efetivando a atividade de defesa. Ao contrário do projétil que é completamente removido da tela, o robô destruído fica movimentando-se horizontalmente em uma área do jogo - como podemos ver na Figura 5 - estando dividido em três partes (cabeça, corpo e pés) e não apresentando mais cor. Existe um elemento do jogo responsável por recuperar estes robôs destruídos. Esse elemento é a nave de reciclagem.

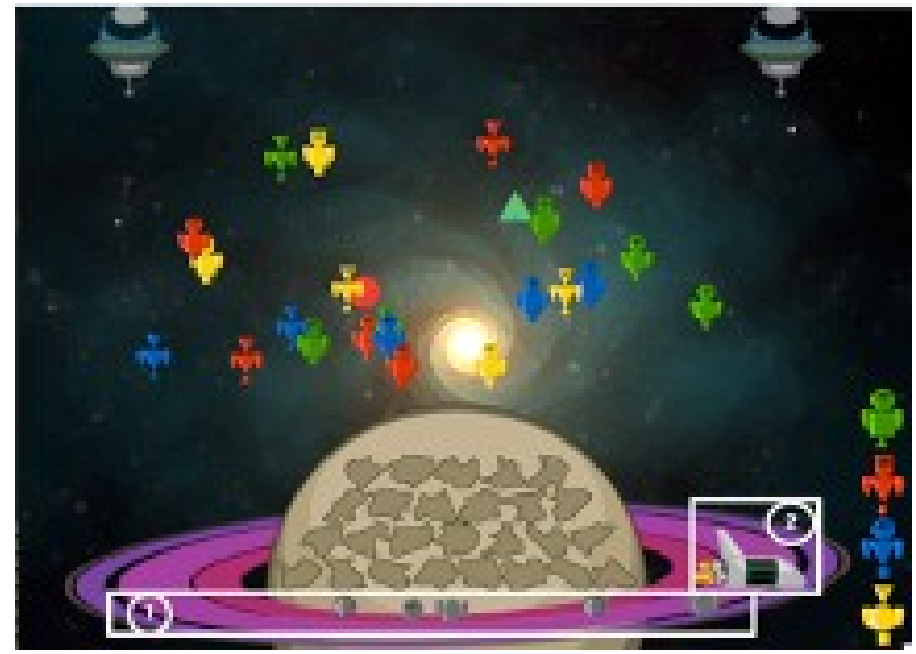

Figura 5 . Robôs destruídos e nave de reciclagem

De acordo com isso, a instância psíquica isolada não é suficiente para colorir o mapa, já que é preciso usar reflexos de atenção e percepção atrelados à motricidade aplicada ao mouse ou à tela "touch" para evitar que os projéteis atinjam o planeta. Nesse ponto podemos afirmar que é impossível jogar sem colaborar de forma estratégica, além disso observamos aqui o aparecimento da articulação da instância psíquica com instância somestésica para alcançar o êxito.

A nave de reciclagem movimenta-se horizontalmente e possui um gancho que, quando ativado, permite ao jogador que a estiver controlando, recuperar os pedaços que estiverem disponíveis para reciclagem. Enquanto o gancho está ativado, a nave não pode se movimentar. Como os pedaços dos robôs estão em movimento, cabe ao jogador decidir o melhor momento para usar o gancho e o melhor momento para movimentar a nave. $\mathrm{O}$ jogador deve recuperar inicialmente o pé, seguido pelo corpo e pela cabeça de um formato de robô específico. Quando as três partes de um robô com um determinado formato são capturadas pela nave de reciclagem, um robô é recuperado, ficando novamente disponível para a atividade de defesa. A cor deste robô é determinada automaticamente de acordo com a escassez de robôs naquela forma/cor durante o jogo.

As atividades, e a ordem em que são executadas, podem ser vistas no diagrama de atividades da Figura 6. Enquanto o mapa do jogo não for completamente pintado, os jogadores podem alternar ou continuar executando as três atividades do jogo (pintar o mapa, defender projéteis com o robô de defesa e 
recuperar robôs com a nave de reciclagem). As atividades são limitadas apenas pela quantidade de elementosdisponíveis por atividades (ex: se existem robôs de defesa disponíveis) e por já estarem sendo realizados por outros jogadores, por exemplo, a nave de reciclagem pode ser operada apenas por um jogador por vez.

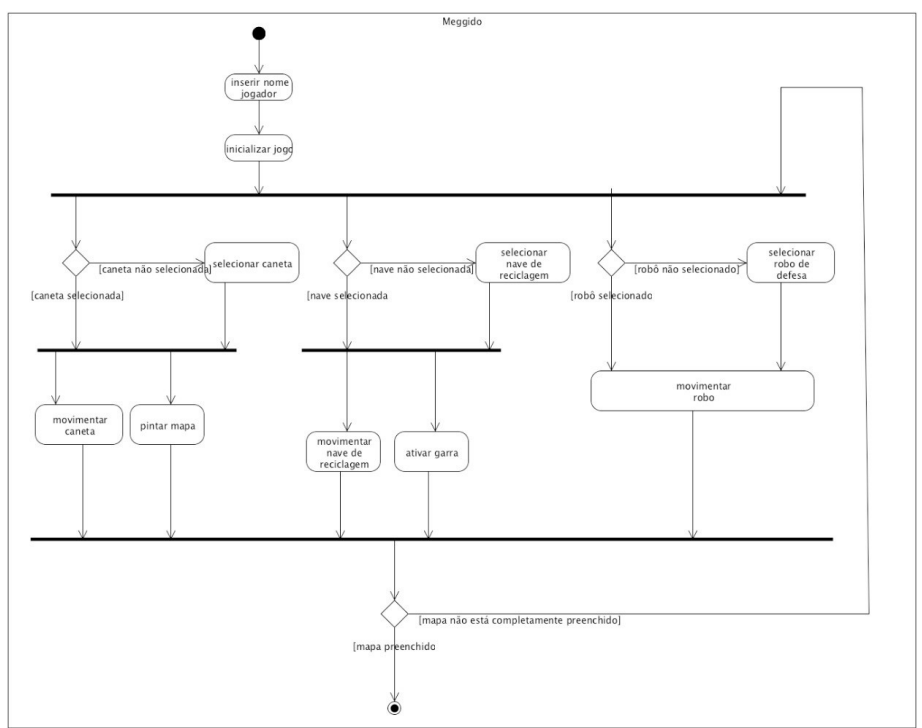

Figura 6 . Diagrama de atividades com a sequência de ações

Com a aplicação deste game foram elaboradas métricas para o diagnóstico da instância nativa de cada aluno, sendo algumas destas métricas listadas na Tabela

Tabela 1. Descrição do observável das unidades interacionais 1.

\begin{tabular}{|c|c|}
\hline Atividade & Regime do Funcionamento das Instâncias \\
\hline Pintar o mapa & $\begin{array}{l}\text { Psiquismo: Se o mapa é pintado corretamente na maior parte das vezes e } \\
\text { a canetanão é muito movimentada em relação a movimentação média dos } \\
\text { jogadores. } \\
\text { Somestesia: Se as canetas são movimentadas acima da média dos outros } \\
\text { jogadores eum percentual acima da média das tentativas incorretas de } \\
\text { pintar o mapa. }\end{array}$ \\
\hline $\begin{array}{l}\text { Recuperar } \\
\text { robô }\end{array}$ & $\begin{array}{l}\text { Psiquismo: Quando a proporção entre o número de robôs recuperados e o } \\
\text { número devezes em que a garra é ativada ou a nave é movimentada é } \\
\text { inferior à média dos outros jogadores. } \\
\text { Somestesia: Quando a proporção entre o número de robôs recuperados } \\
\text { e o númerode vezes em que a garra é ativada ou a nave é movimentada } \\
\text { é superior à média dosoutros jogadores. }\end{array}$ \\
\hline $\begin{array}{l}\text { Defender } \\
\text { projéteis }\end{array}$ & $\begin{array}{l}\text { Psiquismo: Pouca movimentação dos robôs e baixa taxa de defesa em } \\
\text { relação amédia dos outros jogadores. } \\
\text { Somestesia: Grande movimentação dos robôs de defesa e baixa taxa de } \\
\text { defesa emrelação a média dos outros jogadores. }\end{array}$ \\
\hline
\end{tabular}

Para a análise dos dados foram observadas as métricas: tempo de uso do 
mouse, deslocamento do mouse no jogo, objetos escolhidos para a ação, movimento realizado com o objeto e a utilização destes objetos, visando inferir qual é o comportamento predominante no aluno: egocêntrico anacrônico, articulado, tangente somestesia ou tangente psiquismo.

\section{Solução Proposta}

Este artigo se propõe a criar um engenho computacional para verificar em modelo tecnológico que torne possível os registros e a viabilização de análises objetivas derivadas do modelo empírico denominado 'Psicogenética Educacional'. Para construir o modelo empírico usou-se a observação de construtos/comportamentos etários como marcadores quali-quantitativos. Para organizar fatores diferenciais dos comportamentos, criam-se dosagens das habilidades mais expressivas na pessoa, das quais sua transmissão nas etapas do desenvolvimento e a localização nas áreas cerebrais são evidentes.

Verifica-se, portanto, pela mensuração na faixa etária da adolescência, através de um engenho computacional, quanto se produz de inter-relação em trabalho colaborativo e o quanto se promove de desenvolvimento cognitivo em atividades educacionais. Esta pesquisa estuda se e quando o fazer colaborativo é em si um marco provocador e efetuador da competência reciprocativa nas condições do público alvo, considerando o perfil de predisposição de cada usuário

\section{Análise dos Resultados}

Os alunos no regime de enturmação tribal tendiam a se isolar para atingirem o objetivo sozinhos. Nos primeiros minutos de jogo, formava-se um silêncio entre os participantes para investigar as regras. As primeiras ações eram de pintar o mapa. Muitos deles usavam os robôs de defesa para tentar colorir o mapa, resultando em falta de defesa dos tiros, além de amontoar robôs sobre o mapa.

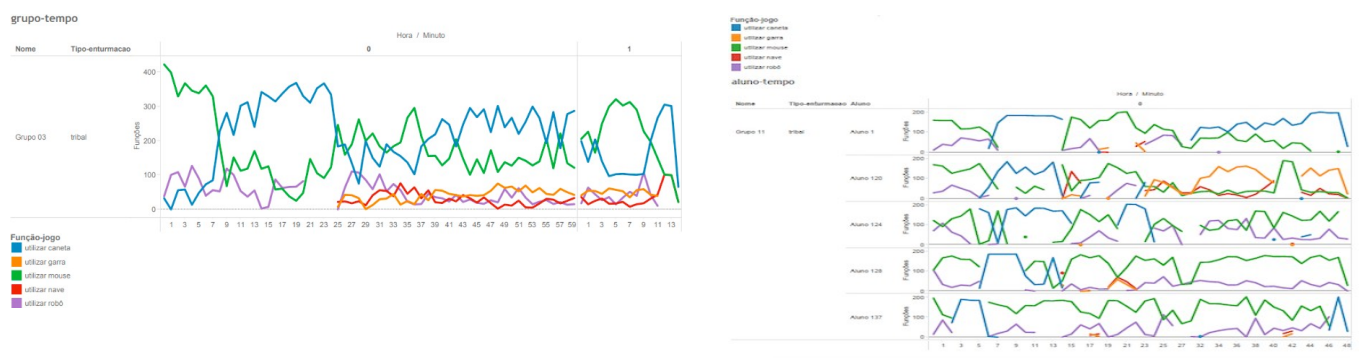

\section{Figura 8 e 9 . Gráfico da série temporal de eventos ocorridos ao longo do game}

Na sequência das descobertas das regras vinha a defesa dos tiros com os próprios robôs. Em paralelo, os grupos aprendiam a pintar o mapa com os robôs lápis. A última regra a ser descoberta era da nave de reciclar robôs para que eles voltassem a poder defender os tiros das naves inimigas. Nas figuras 8 e 9, têm-se os gráficos do grupo 3 do colégio 1, nela pode-se ver o início das ações, destacando que inicia com o uso do robô e da caneta e, a 25 minutos do início do jogo, inicia o uso da nave e da garra. Estas séries temporais demonstram as iniciativas dos alunos de assumir outras funções para mitigar os desafios que vão surgindo ao longo do jogo. A análise destas séries permite construir um perfil cognitivo do 
aluno baseado na persistência em desempenhar cada função específica. A integralização deste perfil pode ser observada na Figura 10.

Na Figura 10, apresenta o perfil do aluno do grupo 3 do colégio 1. Este grupo finalizou o jogo com 1h13min.

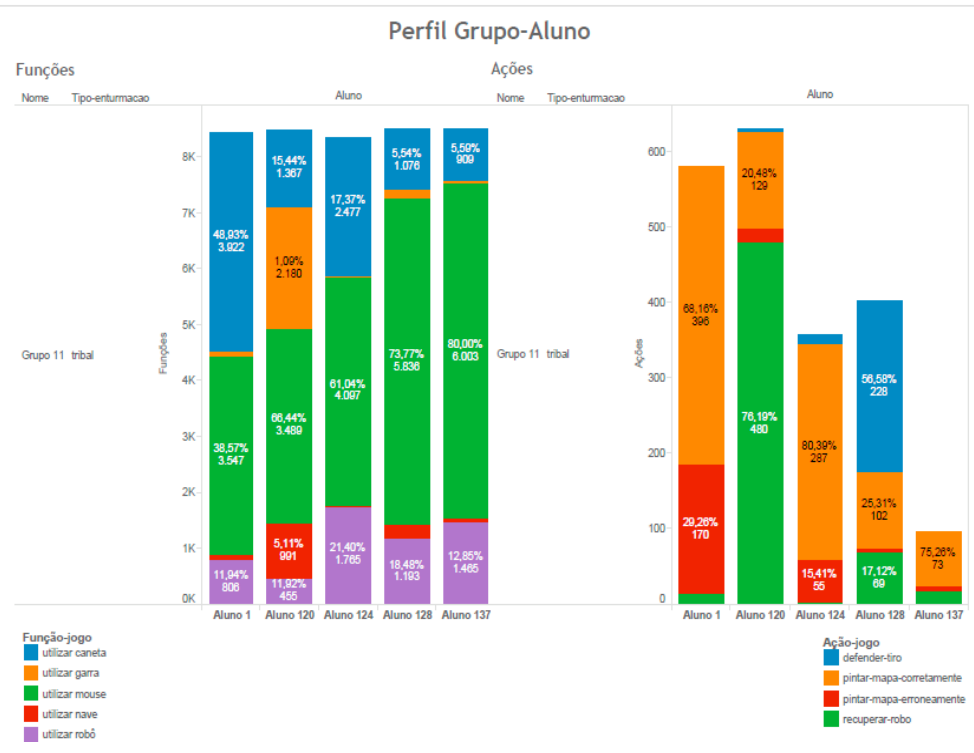

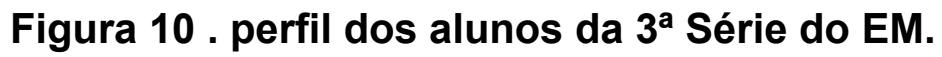

Este grupo não finalizou o jogo. Neste grupo 11, havia dois alunos com deficiência física que se dedicaram a pintar o mapa compulsivamente. As ações deles não levavam ao resultado 147 esperado, cometendo repetidos erros nesta função. Um exemplo é o aluno 137 que teve predominância do comportamento egocêntrico anacrônico, fazia muita função, mas era ineficiente na ação. A aplicação constata que a velocidade dos tiros das naves inimigas não interfere no resultado do jogo. É claro que o diferencial para se obter êxito no jogo está na qualidade da capacidade inter-relacional dos participantes. Nesta enturmação, as ações de reciclar e pintar o mapa corretamente são primordiais para finalizar o jogo.

\section{Considerações Finais e Conclusões}

Este A solução apresentada nesta pesquisa indica que o jogo computacional colaborativo é uminstrumento eficaz de para mediação capaz de mensurar o egocentrismo anacrônico, o tangenciamento e a articulação das instâncias dos estudantes de ensino médio.

A partir destas mensurações, os professores podem intervir nos alunos que se enquadramem cenários deficitários. Isto pode ser feito através das matérias acadêmicas para ativar as instâncias prejudicadas e promover a articulação. No jogo, percebe-se pelos dados e pelaobservação presencial quais participantes tendem a resolver o desafio sozinhos e quais buscamo diálogo e a colaboração para atingir um resultado positivo.

O presente estudo contribui com as pesquisas computacionais educacionais colaborativas, que têm na informática seu instrumento para ativar e 
desenvolver as estruturas cerebrais e por correlação, os funcionamentos interrelacionais, contemplando, nesse caso, os alunos do ensino médio. A Educação Básica deve considerar as mediações feitas pelos educadores/aplicadores de forma manual (no caso de jogos tangíveis) e as para-mediações feitas pelos jogos computacionais colaborativos, automaticamente.

Acredita-se que esse estudo contribui para a democratização do desenvolvimento integral da formação dos estudantes do ensino médio, tanto da rede pública quanto da rede particular de ensino. Entende-se que os professores têm disponível um jogo computacional colaborativo que agiliza os processos de construção da "Inteligência Coletiva" de seus estudantes, integrando-os ao universo do conhecimento altruísta e dativo. Acredita-se, ainda, contribuir para a ciência ao praticar indicadores matematizáveis da teoria Psicogenética, de tal forma que os computadores possam entender suas regras.

A análise dos resultados demonstra que é possível comprovar a capacidade dos estudantes de conservar as "estruturas familiares" [INHELDER 1996] de inter-relação, apesarde manifestarem outras estruturas anacrônicas. Isto é, os dados mostram que se produz novas estruturas cerebrais de inter-relação quando estão em enturmação seletiva, possibilitando aos alunos participantes viverem seu melhor nível sazonal (desenvolvimento compatível com a idade cronológica) de articulação das instâncias somestesia e psiquismo, da comunicação e praticar a colaboração acadêmica em padrão de Inteligência Coletiva [PIMENTEL \& FUKS 2012].

A resposta educacional dessa pesquisa concretiza-se em um engenho computacional capaz de medir a qualidade dos relacionamentos presenciais e digitais entre os estudantes do ensino médio no processo de produção acadêmica. Portanto, a hipótese de que para enfrentar o problema do baixo rendimento escolar e do egocentrismo anacrônico é preciso melhorar as ferramentas digitais colaborativas, dotando-as com os códigos da mobilização do interagir e do interrelacionar-se específicos nesta faixa etária, tem forte indícios de ser verdadeira.

A função social atribuída dessa maneira, à inter-relação, instiga o estudante do ensino médio a adquirir um desenvolvimento de competências de modo que se torne uma pessoa autônoma, capaz de produzir livre e de forma socializada, isto é, proporcionar um meio mediacional digital para promover a articulação ótima entre as instâncias somestésica e psíquica.

\section{Referências}

Boulic, R. and Renault, O. (1991) "3D Hierarchies for Animation”, In: New Trends in Animation and Visualization, Edited by Nadia Magnenat-Thalmann and Daniel Thalmann, John Wiley \& Sons ltd., England.

Bavelier, D., Achtman, R. L., Mani, M., and Föcker, J. (2012). Neural bases of selective attention in action video game players. Vision Res. 61, 132-143. doi: 10.1016/j.visres.2011.08.007.

Inhelder, Bärbel [et al.]. O Desenrolar das descobertas da criança: pesquisa acerca das microgêneses cognitivas. Trad. Eunice Gruman. Porto Alegre: Artes Médicas, 1996. 
Krause, K. K. G., Hounsell, M. S. \& Gasparini, I. (2020). Um modelo para interrelação entre funções executivas e elementos de jogos digitais. Revista Brasileira de Informática na Educação - RBIE, 28, 596-625. DOI: 10.5753/RBIE.2020.28.0.596

Metcalfe, Janet; Shimamura, Arthur P. Metacognition: knowing about knowing. Cambridge, Massachusetts. 1994. P. 334.

Moura, Waldir Siqueira; DIAS, Angélica Fonseca da Silva; FRANÇA, Juliana Baptista dos Santos; BORGES, Marcos Roberto da Silva; OLIVEIRA, Jonice de Oliveira Sampaio. ColabSaber: Um framework de suporte pedagógico na construção colaborativa de saberes. In: WORKSHOP DE INFORMÁTICA NA ESCOLA, 26. 2020, Evento Online. Anais [...]. Porto Alegre: Sociedade Brasileira de Computação, 2020. p. 61-70. DOI: https://doi.org/10.5753/cbie.wie.2020.61.

Oliveira, R.N.R. [et al.] (2019). Avaliações em Jogos Educacionais: instrumentos de avaliaçãoda reação, aprendizagem e comparação de jogos. Congresso Barsileiro de Informática na Educação - CBIE, 28, 972-981. DOI: http://dx.doi.org/10.5753/cbie.sbie.2019.972

Palaus, M., Marron, E. M., Viejo-Sobera, R., \& Redolar-Ripoll, D. (2017). Neural basis of video gaming: A systematic review. Frontiers in Human Neuroscience, 11. Doi: 10.3389/fnhum.2017.00248 [GS Search].

Piaget, Jean. A noção do tempo na criança. Editora Record. Rio de Janeiro. 1964. P. 321.

, A psicologia da Inteligência. Livros Horizonte. Lisboa. 1967. P. 201.

Pimentel, Mariano \& Fuks, Hugo (Colaboradores), Sistemas Colaborativos, Editora Campus, Sociedade Brasileira de Computação, Brasil. 2012. P. 375.

Shimamura, A.P. - The Role of Metacognition in Problem Solving, 1994.

Tutte, W. (1968). The four-color problem, by Oystein Ore. Academic Press, New York, 1967. xv 259 pages. Canadian Mathematical Bulletin, 11(1), 161-163. doi: $10.1017 / \mathrm{S} 0008439500028915$

Vossel, S., Geng, J. J., and Fink, G. R. (2014). Dorsal and ventral attention systems: distinct neural circuits but collaborative roles. Neuroscientist 20, 150-159. doi: $10.1177 / 1073858413494269$

Wendel, V., Gutjahr, M., Göbel, S. et al. Designing collaborative multiplayer serious games. Educ Inf Technol 18, 287-308 (2013). https://doi.org/10.1007/s10639-0129244-6

Xavier JR., Joaquim Ferreira. "A Psicogenética - Demarcando os processos da vida". Tremembé: VespeR Editora. 2004. P. 337.

, "Psicognética Educacional". Tremembé: VespeR Editora. 2004. P. 256. 